\title{
Revisiting the Role of Natural Killer Cells in Non-Alcoholic Fatty Liver Disease
}

\author{
María Luz Martínez-Chantar ${ }^{1,2}$, Teresa C. Delgado ${ }^{1}$ and Naiara Beraza ${ }^{3 *}$ \\ ${ }^{1}$ Liver Disease Laboratory, Center for Cooperative Research in Biosciences (CIC bioGUNE), Basque Research and \\ Technology Alliance, Derio, Spain, ${ }^{2}$ Centro de Investigación Biomédica en Red de Enfermedades Hepáticas y Digestivas \\ (CIBERehd), Derio, Spain, ${ }^{3}$ Gut Microbes and Health Institute Strategic Programme, Food Innovation and Health Institute \\ Strategic Programme, Quadram Institute Bioscience, Norwich Research Park, Norwich, United Kingdom
}

Non-Alcoholic Fatty Liver Disease (NAFLD) is the most common form of chronic liver disease. The histological spectrum of NAFLD ranges from simple steatosis to chronic inflammation and liver fibrosis during Non-Alcoholic Steatohepatitis (NASH). The current view is that innate immune mechanisms represent a key element in supporting hepatic inflammation in NASH. Natural Killer (NK) cells are lymphoid cells and a component of the innate immune system known to be involved in NASH progression. Increasing evidence has shed light on the differential function of circulating and tissue-resident NK cells, as well as on the relevance of metabolism and the microenvironment in regulating their activity. Here, we revisit the complex role of NK cells as regulators of NASH progression as well as potential therapeutic approaches based on their modulation.

Keywords: NK cells, NAFLD, NASH, metabolism, obesity

\section{INTRODUCTION}

Non-Alcoholic Fatty Liver Disease (NAFLD) is the most common form of chronic liver disease in western countries and affects over $25 \%$ of the population globally (1). NAFLD pathophysiological effects extend beyond liver-related morbidity and mortality as NAFLD also increases the risk of T2DM, cardiovascular (CVD) and cardiac diseases, and chronic kidney disease (CKD) (1). NAFLD comprehends a group of conditions that share, as a common feature, the accumulation of fat in the liver as a result of non-alcoholic and non-viral causes. The histological spectrum of NAFLD ranges from simple steatosis, usually considered rather benign, to Non-Alcoholic Steatohepatitis (NASH), characterized by lobular inflammation; patients with NASH are more likely to progress to advanced fibrosis, cirrhosis (2) and eventually to hepatocellular carcinoma (HCC) (3).

Accepted: 25 January 2021

Published: 18 February 2021

Citation:

Martínez-Chantar ML, Delgado TC and Beraza N (2021) Revisiting the

Role of Natural Killer Cells in Non-Alcoholic Fatty Liver Disease.

Front. Immunol. 12:640869. doi: 10.3389/fimmu.2021.640869

\section{INFLAMMATION AS THE HALLMARK OF THE PROGRESSION FROM NON-ALCOHOLIC FATTY LIVER DISEASE (NAFLD) TO NON-ALCOHOLIC STEATOHEPATITIS (NASH)}

Chronic inflammation is a hallmark of NASH, characterized by profound dysregulation of the different innate and adaptive immune cell compartments as reviewed elsewhere $(4,5)$. 
Briefly, NASH is characterized by robust recruitment of immune cells into the liver where they become activated (5). While a dysregulated immune response can further exacerbate liver disease [reviewed in (6)], the inflammatory response occurring early during liver injury may be important for healing and tissue repair $(7,8)$, adding complexity to the implication of immune cells in the pathogenesis of NAFLD/NASH. Singlecell-based transcriptomics studies showed that immune cellular heterogeneity and dysregulation are concomitant with the pathogenesis of NAFLD/NASH in patients (9) and in dietinduced obesity (DIO)-NASH mice $(10,11)$. The frequencies of different immune cell compartments are altered during NAFLD and the specific role of some of these immune cell populations in promoting NASH has been well-established. For example, $\mathrm{KCs}$ are enriched in NASH livers, where produce inflammatory cytokines and facilitate the development of fibrosis and HCC [reviewed in $(12,13)]$. Likewise, neutrophils, are recruited into the liver during NASH in response to several chemokines contributing to the progression of NASH and pathogenesis of HCC (14). On the other hand, CD4 $+\mathrm{T}$ cells and regulatory $\mathrm{T}$ (Tregs) are decreased in experimental NASH, whereas IL17producing $\mathrm{T}$ cells increased and CD8 $+\mathrm{T}$ cells were activated (15). In agreement with the different frequencies observed, $\mathrm{T}$ helper 22 (Th22) cells, a subset of CD4+ T cells, and regulatory $\mathrm{T}$ (Treg) cells appear to hamper NAFLD progression whereas Th17 and cytotoxic T (Tc) cells further promote liver injury and fibrosis progression [reviewed in (16)].

The importance of other populations of immune cells, such as DC, NKT cells, B cells, and NK cells in promoting NASH is less clear and is still under debate.

\section{NATURAL KILLER CELLS: A HETEROGENOUS MULTIFUNCTIONAL POPULATION}

Although adaptive immunity promotes liver inflammation in NAFLD, current views suggest that innate immune mechanisms are a key element supporting hepatic inflammation in NASH (17). NK cells, a component of the innate immune system, were first functionally identified in 1975 as a unique group of lymphocytes based on the presence of distinctive cytoplasmic granules (18-21). Functionally, NK cells kill their targets via secretion of lytic granules that contain pore-forming perforin and apoptosis-inducing granzymes $(22,23)$. In humans, there are two subsets of NK cells based on the relative expression of specific surface markers: the $\mathrm{CD} 56^{\mathrm{dim}} \mathrm{CD} 16^{+}$phenotype and the $\mathrm{CD} 56^{\text {bright }} \mathrm{CD} 16^{\text {dim-/+ }}$ phenotype. CD56 ${ }^{\text {dim }} \mathrm{NK}$ cells are important for immediate cytotoxic killing of target cells, whereas CD56 $6^{\text {bright }} \mathrm{NK}$ cells require upregulation of the cytotoxic machinery before achieving cytotoxic potential (24). NK cells originate in the bone marrow and undergo a complex maturation process during which they acquire their effector functions; they then disperse and are present throughout lymphoid and nonlymphoid tissues. The lung has the highest frequency of NK cells amongst its lymphocytes, followed by the liver, peripheral blood, spleen, bone marrow, lymph nodes, and thymus.
Hepatic NK cells, originally called "Pit cells," are situated inside the sinusoidal lumen, adhering to endothelial and KCs; morphologically they are defined as large granular lymphocytes (LGLs) and functionally as hepatic (liver-associated) NK cells (25). Human hepatic NK cells are a heterogeneous population, phenotypically and functionally, and include liverresident $\mathrm{NK}$ cells $\left(\mathrm{CCR}^{+} \mathrm{CXC}^{\mathrm{R}+} \mathrm{CD} 9^{+}\right)$, memory-like $\mathrm{NK}$ cells $\left(\mathrm{CXCR}^{+}{ }^{+} \mathrm{CD} 94 / \mathrm{NKG} \mathrm{C}^{+}\right.$) and transient conventional NK cells mainly represented by recirculating $\mathrm{NK}$ cells (predominantly CD56 ${ }^{\text {dim }} \mathrm{CD} 16^{+} \mathrm{NK}$ cells) in the liver blood system [reviewed in (26)]. While recirculating NK cells play a major role in host rejection of tumors and virus-infected cells (27); the liverresident NK cells have an increased killing activity, express higher levels of cytotoxic mediators (e.g., IFN $\gamma$ and TNF), and expression of CD69; an acute activation marker expressed transiently on recently activated lymphocytes. Memory-like NK cells, show unique adaptive traits and hapten-specificity, indicating that NKs can mediate long-lived, antigen-specific adaptive recall responses (28). However, the existence of a specific viral-antigen recognized by a given NK receptor expressed on human memory-like NK cells has not be yet demonstrated.

As key components of the liver innate immune system, hepatic NK cells can kill pathogens, tumor cells, stressed hepatocytes and HSCs, either directly or indirectly through the production of cytokines. NK cells can also target DCs, KCs, T cells, B cells, and endothelial cells through innate immunorecognition or by producing cytokines [e.g., IFN-gamma (IFN $\gamma$ ), tumor necrosis factor (TNF), interleukin-10 (IL-10)], chemokines and growth factors. The ability of hepatic NK cells to kill target cells is regulated by opposing signals from inhibitory and stimulatory receptors on their surfaces [reviewed in $(29,30)]$.

In the last years, NK cells have been described as important intermediates in several types of liver disease, including viral hepatitis, where they have a functional dichotomy featuring conserved or seldom enhanced cytolytic activity, together with dysfunctional cytokine production contributing to the persistence of the virus (31). NK cells can modulate drug-induced liver injury by direct interaction with hepatocytes resulting in cytotoxicity and IFN $\gamma$ production (32). NKs are also relevant in liver cancer, where very recently the presence and dysfunction of liver-resident NK cells was reported and could therefore provide a new strategy for immune checkpoint-based targeting (33). Herein, we revisit the important role of NK cells in the pathogenesis and progression of NASH.

\section{NATURAL KILLER CELLS IN NON-ALCOHOLIC FATTY LIVER DISEASE (NAFLD): FREQUENCIES AND ACTIVATION}

To date, the presence, regulation and function of NK cells during NAFLD remains controversial (Table $\mathbf{1}$ for a summary of major findings to date). In recent years, several studies have found that the frequency of circulating NK cells in obese individuals is lower than in lean individuals, both for adults $(36,39)$ and children $(38)$. Reduced frequency was associated with dysfunctional activity and characterized by lower levels of 
TABLE 1 | NK cells characteristics and activity during human and experimental NAFLD/NASH.

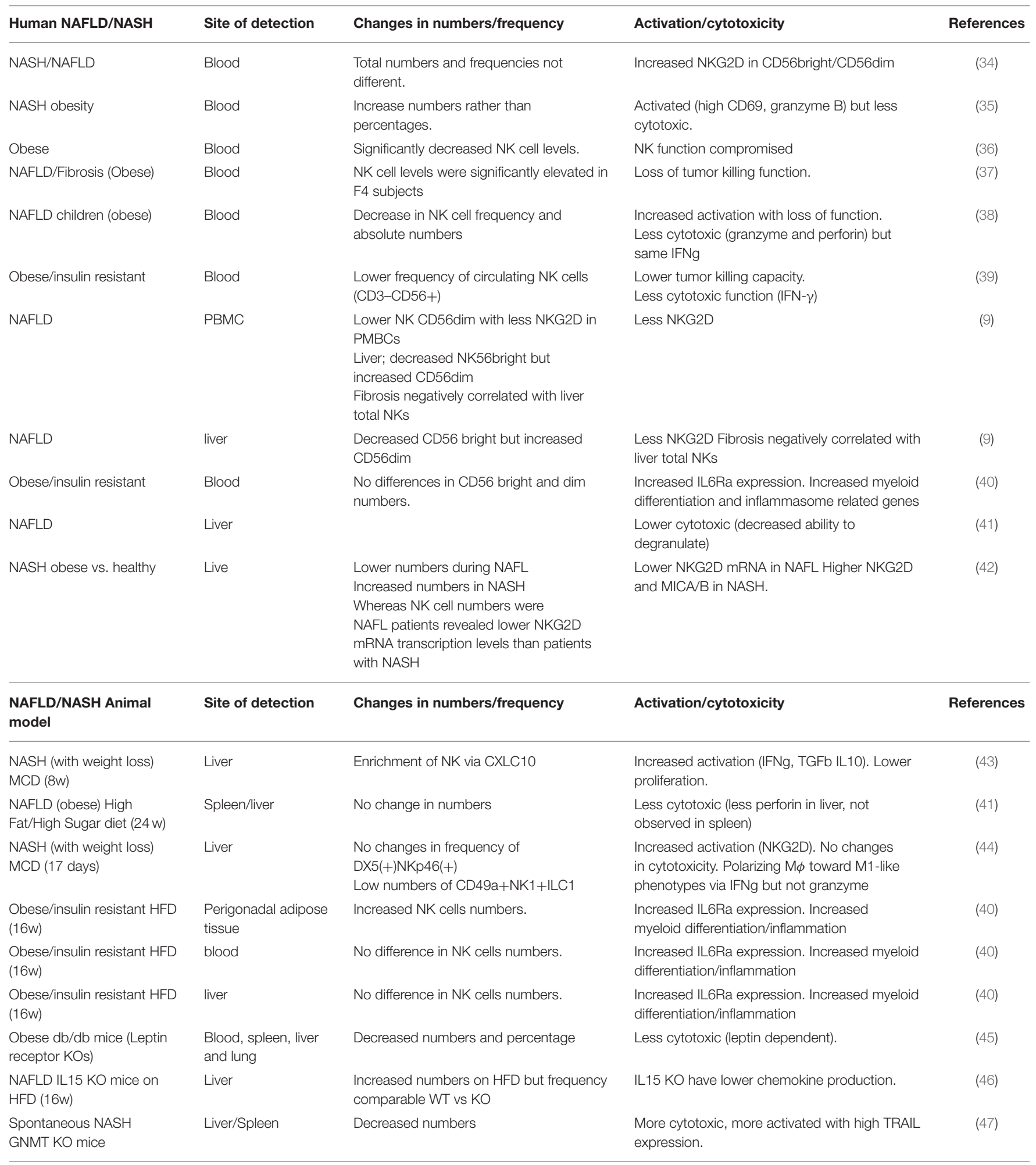

IFN $\gamma$ (39) and reduced cytotoxic activity, with less granzyme B and perforin production and a reduced capacity to kill tumor cells $(36,38,39)$. In line with this, circulating NK cells from obese patients appeared activated, with higher $\mathrm{CD}^{+} 9^{+}$expression but showed reduced cytokine production and cytotoxicity than cells from lean patients (35). Most recently, NAFLD patients were shown to have a lower frequency of CD $56^{\mathrm{dim}} \mathrm{NK}$ cells with lower expression of the activating receptor NKG2D compared 
with healthy individuals (9). Comparable results were described in murine models of obesity where the percentage and total numbers of circulating and tissue-resident NKs were reduced in obese $\mathrm{db} / \mathrm{db}$ mice deficient in the leptin receptor, compared with controls (45).

In apparent contradiction, other studies described no changes in either frequency or absolute numbers of circulating CD56 $6^{\text {bright }}$ and CD56 ${ }^{\text {dim }}$ NK cells in obese, NAFL, or NASH patients (34, 40 ), and similar cytokine production and cytotoxic activity (34). Interestingly, while the frequencies of CD56 ${ }^{\text {bright }}$ and CD56 $6^{\text {dim }}$ NK cells were maintained within the different treatment groups, differences in the phenotype/cytokine receptors were found. Thus, $\mathrm{CD}^{-}{ }^{-} \mathrm{CD} 56^{+} \mathrm{NK}$ cells from obese individuals (and in animal models of obesity and insulin resistance) had significantly higher expression levels of the interleukin-6 receptor (IL6R) (40). Likewise, despite similar frequencies, NK cells from NASH patients had higher levels of NKG2D than NK cells from healthy individuals, while no differences were observed in NAFLD patients (34). Of relevance, liver fibrosis is a key determinant for activation of circulating NK cells. Thus, CD56 ${ }^{\mathrm{dim}} \mathrm{NK}$ cells were more cytotoxic in patients with low fibrosis scores while the tumor-cell-killing capacity of CD $56^{\text {dim }}$ cells was significantly reduced in patients with high fibrosis scores (37). Differences in disease stage in the human cohorts studied (advanced NASH with fibrosis vs. NAFLD), could partly explain differential expression of NKG2D and circulating NK cell frequency.

NAFLD is a multisystemic disease and other organs besides the liver are involved in this pathology, e.g., the adipose tissue. Both CD56 ${ }^{\text {bright }}$ and CD56 $6^{\text {dim }} \mathrm{NK}$ cells are present in adipose tissue (with $\mathrm{CD} 56^{\text {bright }}$ being enriched) and are characterized by having distinct homing markers compared to blood NKs (e.g., CD25, CD69, and CD49a) during human and murine NASH $(48,49)$. The frequency and activity of NK cells in adipose tissue was comparable in healthy, NAFLD and NASH patients (with mild phenotypes; not including high BMI and severe cirrhosis) (34). However, studies in mice have shown increased accumulation of NK cells in perigonadal adipose tissue after feeding with a high-fat diet (HFD) that present a different transcriptional profiling, including increased IL6Ra and myeloid markers; Csf1 (40). The inhibition on these myeloid-related pathways significantly reduced obesity and insulin resistance, supporting that the tissue-specific characteristic of adipose NK cells contributes to the progression of NASH (40). The relevance of the NK cells-macrophages crosstalk was further supported by Wensveen and colleagues that showed increased expression of NK cell receptor NCR1 (NKp46)-activating ligands on adipocytes in mice after feeding with an HFD. This activated proliferation of NK cells and increased production of IFN $\gamma$, which further supported the infiltration and activation of macrophages in this tissue, key to maintain the systemic inflammatory status and insulin resistance characteristic of NASH (50). Likewise, the depletion of the transcription factor E4bp4 in NK cells led to the reduction of adipose tissue macrophages in obese mice, further underlining the relevance of the NK cells-macrophage interaction in contributing to obesity and insulin resistance (48).

Similarly to what was described in the adipose tissue, several studies found comparable NK frequencies in the livers of obese and lean patients (41) and in mice during experimental NASH, though liver NK cells exhibited increased cytokine (IFN $\gamma$ ) production (44) but reduced cytotoxic capacity, which was negatively correlated with disease severity (41) (Figure 1). In contrast, enrichment of NK cells in the liver was observed after consumption of a methionine and choline-deficient (MCD) diet (43). Accordingly, Kahraman and colleagues found that liver fibrosis in NASH patients was associated with an increased presence of hepatic NK cells with high NKG2D expression and elevated gene and protein expression of its ligands MICA/B in the liver parenchyma, while in NALFD patients intrahepatic NK cell numbers were reduced $(9,42)$. The expression of NKG2D in NK cells can be downregulated by factors like TGF $\beta$ but activated by cytokines (i.e., IL-2 and IL-15), and ligands including MICA/B in humans and MULT-1, RAE, and HS90 in mice in stressed/damaged lipid-loaded hepatocytes (47, 51, 52) (Figure 1). MICA can be regulated by different immune cells including activated T cells (53) and macrophages in response to TLR activation (54), and its expression was found to be upregulated in NASH but not in NAFLD patients, accordingly to the differential NKG2D expression (42). MICA is a highly polymorphic gene, and a very recent study described the association between different MICA alleles in circulation and pathogenic indicators of NASH vs. NAFLD in the liver. Whether these different alleles could differentially influence NKG2D expression remains undefined.

Overall, even though improved characterization of NK cell markers has revealed distinct cell types, the inability to distinguish between liver-resident and circulating NK cells may explain apparently contradictory results. Indeed, most in vitro studies use circulating NK cells from human blood or mouse spleens as few liver-resident NK cells can be purified from a mouse's liver, significantly prohibiting adoptive transfer. The demonstrated differential and tissue-dependent regulation of NK cells highlights the importance of microenvironment in regulation in NK cell function and may explain the contradictory results observed.

\section{IMMUNOMETABOLISM A KEY DETERMINANT IN NATURAL KILLER CELLS ACTIVITY IN NASH}

In many different pathological conditions activation of immune cells involves metabolic reprogramming toward aerobic glycolysis and a lower reliance on oxidative phosphorylation (OXPHOS) (55). As with other immune cells, metabolic reprogramming of $\mathrm{NK}$ cells depends on the type and duration of the stimuli (56), and NK cell-intrinsic metabolic processes influence their performance. While resting $\mathrm{NK}$ cells have low basal metabolic rates, i.e., low OXPHOS and glycolysis, they still sustain acute NK cell responses. Under different conditions and in response to particular cytokines, NK cells can either increase reliance on OXPHOS to produce IFN $\gamma$ and support cytotoxic activity via granzyme production $(57,58)$, or upregulate expression of nutrient transporters thereby increasing glucose uptake and feeding glycolysis to meet the elevated energy 


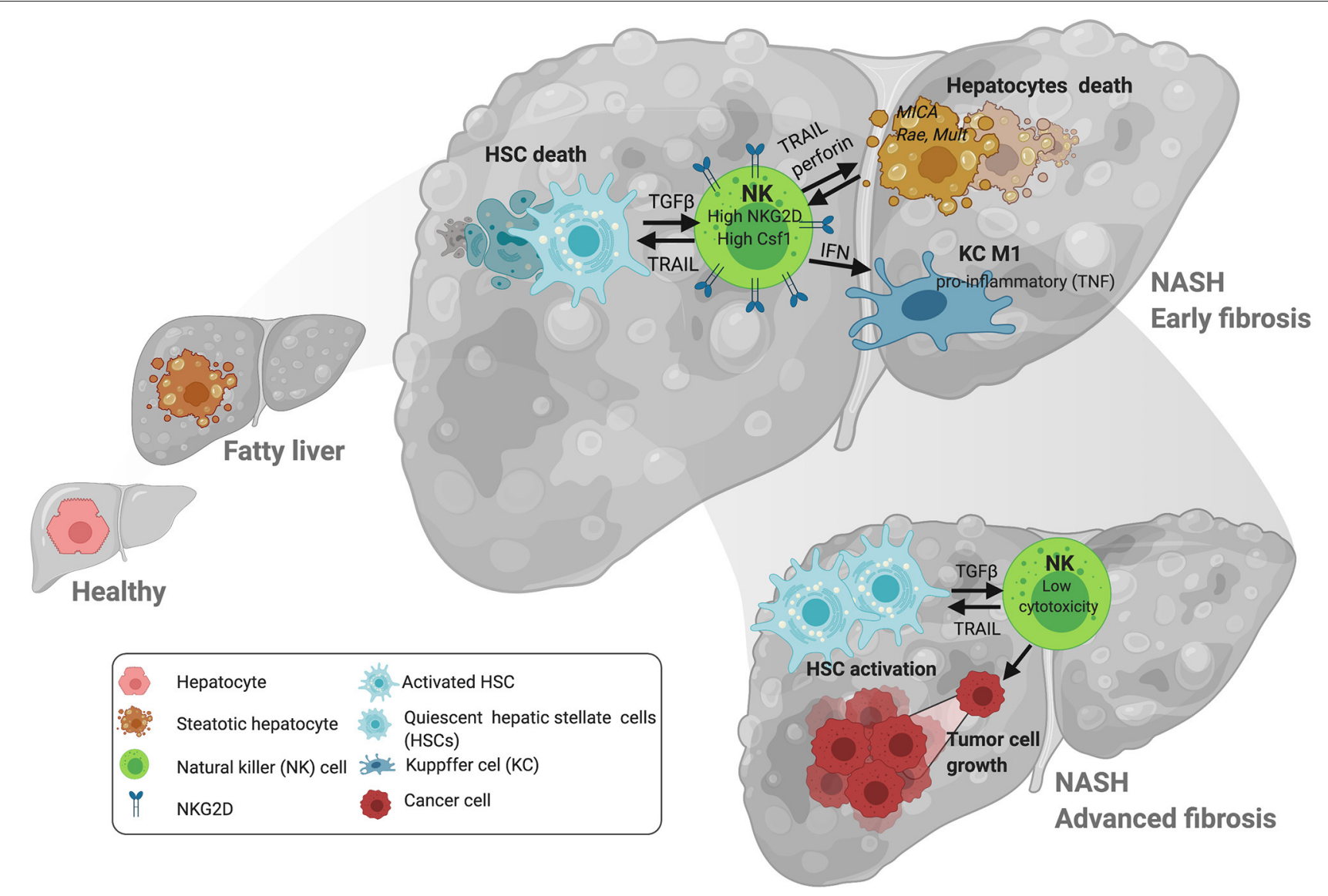

FIGURE 1 | NK cell interactions with liver cells during NAFLD/NASH progression. At early stages of NAFLD, NK cells promote TRAIL-mediated death of hepatic stellate cells (HSC). NK cells promote the activation of other immune cells in the liver including macrophages via IFN- $\gamma$. Lipid accumulation in hepatocytes contributes to the expression of stress ligands that may promote the upregulation of the activating receptor NKG2D. This is relevant at later stages of NASH where increased activation of NKG2D by ligands including MICA (in patients) promote activation of NK cells. Loss of cytotoxic and tumoricidal activity in NK cells may contribute to the progression of hepatocellular carcinoma $(\mathrm{HCC})$ at later stages of the disease. Figure created with BioRender.com.

demand (57-60). mTOR plays a key role in this metabolic reprogramming by upregulating glycolysis and overall IFN $\gamma$ and granzyme B production $(57,59,60)$. Cytokines also induce sterol regulatory element-binding protein (SREBP) in NK cells; this is important for controlling glycolysis and OXPHOS via the citrate-malate shuttle (CMS) (not the TCA cycle) independently of its lipid-regulatory function (61). Unlike other lymphocyte subsets, glutaminolysis and the tricarboxylic acid cycle do not sustain OXPHOS in activated NK cells. Glutamine withdrawal, but not the inhibition of glutaminolysis, results in the loss of cMyc protein, reduced cell growth and impaired NK cell responses (62). Activation of NK cells can also be negatively regulated by other factors including transforming growth factor (TGF $\beta$ ) that suppresses cell metabolism inhibiting glycolysis and OXPHOS $(41,63)$.

Recent studies have highlighted the role of microenvironment in activation of NK cells and also in how NK cells adapt the expression of nutrient transporters and their metabolism in different tissue compartments. For example, hepatic CD56 bright NK cells have lower capacity for glucose uptake but higher for aminoacids as they express low levels of GLUT1 but higher CD98 while CD56 ${ }^{\text {bright }}$ NK cells in the blood express high levels of GLUT1 and lower levels of CD98 and CD71 (64). Moreover, CD56 dim (cytotoxic) are less metabolically active than CD56 bright (cytokine IFN $\gamma$ producing) NK cells (57).

In agreement with the observed influence of microenvironment on NK cells metabolic activity, their metabolic function is also severely disrupted during obesity. Indeed, in obese children with NAFLD, blood NK cells are metabolically stressed, showing increased mTOR, glycolysis and mitochondrial reactive oxygen species (ROS) production that associate with a loss of function (38). In obese adults, NK cells had severely impaired tumor-killing capacity; NK cells took up lipids (via increased CD36) during obesity, leading to profound metabolic alterations (a so-called "metabolic paralysis") and, ultimately, to a loss of cytotoxic capacity (39). In more detail, 
lipid-metabolism-related gene expression was altered in lipid-loaded NK cells which showed reduced glycolysis and OXPHOS concomitant with reduced mTOR. These metabolic alterations were confirmed in NK cells from obese patients which was also correlated with impaired proliferation, explaining why fewer NK cells were found in obese patients $(9,36,38,39)$. Lipid-mediated loss of function may lead to tumor development in the context of NASH.

Obesity also promotes the shift of NK cells into an ILC1 phenotype which is associated with lower cytotoxicity and a reduced capacity to kill tumor cells (41). Cuff and colleagues proposed regulation of mTOR by TGF $\beta$ as a mechanism mediating these effects. This could explain discrepancies in the observations of mTOR activation in obese children (with high mTOR) and adults; where low mTOR associates with lower Insulin receptor expression and increased cirrhosis due to lower HSC-killing activity (37).

Overall, both blood and hepatic NK cell activity and metabolism is altered during obesity and insulin resistance, risk factors for NAFLD. Differences in metabolic reprogramming of NK cells associated with NAFLD progression need to be further investigated, as does the therapeutic potential of targeting NK cell immunometabolism for NAFLD treatment.

\section{THE CONTROVERSIAL ROLE OF NATURAL KILLER CELLS-TARGETING DURING NASH PROGRESSION}

Targeting NK cell function in NAFLD has been evaluated using different approaches. For example, mice with impaired cytotoxic capacity (Perforin-KO mice) have reduced liver injury and less fibrosis than controls (35). Absence of IL-15 and IL-15Receptor alpha in $\mathrm{KO}$ mice associated with reduced steatosis that associated with lower inflammation during HFD-induced NAFLD (46). Likewise, the significant protective effects observed in mice lacking TRAIL/TRAIL-Receptor further support the detrimental role of NK cells in NAFLD, via hepatocyte death $(65,66)$, which also mediated disease progression in genetically induced mouse models of NASH $(47,67)$ (Figure 1). Finally, mice deficient in NK cells failed to develop fructose-induced NAFLD (68) and depletion of NK cells decreased infiltration of macrophages into the intra-abdominal adipose tissue, reducing inflammation and insulin resistance (69).

Despite these promising indications that targeting NK cells in NAFLD is beneficial, caution is needed. On one hand, several studies have shown that loss of the cytotoxic activity of NK cells during NASH could potentially contribute to the higher susceptibility of obese/NASH patients to liver cancer at later stages of the disease $(35,41)$. On the other hand, during $\mathrm{NASH}, \mathrm{NK}$ cells are recruited into the liver via mechanisms including chemokine (C-X-C motif) ligand 10 (CXCL10) (43), where they have an antifibrotic effect $(37,43,44,70-74)$. More specifically, $\mathrm{DX} 5^{+} / \mathrm{NKp} 46^{+} \mathrm{NK}$ cells are activated and contribute to limiting tissue damage and fibrosis during NASH by polarizing macrophages into a proinflammatory M1 phenotype via IFN $\gamma$ without affecting their cytolytic function (44) (Figure 1). Potent antifibrotic activity of NK cells relies on their ability to kill activated HSC, the main fibrogenic hepatic cell type, via diverse mechanisms including: expression of NKp46 receptor [NCR1 in mice (70)] and its activating ligand (TRAIL) on target cells (74); reduction of Class-I expression; an increased aKIR:iKIRratio (72); and relevant metabolic changes including to the $\mathrm{PI} 3 \mathrm{~K} / \mathrm{mTOR}$ pathways $(37,71)$. Interestingly, the capacity of NK cells to kill HSC seems to be more relevant at early stages of fibrosis while it is impaired at more advanced stages of fibrosis and insulin resistance (37) (Figure 1). Thus, the increase in NK cells frequency, activation and expression of NKG2D and MIC A/B in livers from NASH patients (42) may be effective initially but futile at more advanced stages of disease, overall contributing to the proliferation and activation of HSC. Alternative mechanisms contributing to the deleterious role of NK cells during NASH include: the development of a "myeloid" phenotype of NK cells as these express high levels of CSF1 and CCR2 (40) (Figure 1); and induction of hepatic ER stress via osteopontin, which contributes to insulin resistance in the context of obesity (75). Adipose tissue-resident NK cells also contribute to obesity-induced insulin resistance in adipocytes via IFN $\gamma$ production leading to macrophage polarization $(48,50,76)$.

Overall, the role of $\mathrm{NK}$ cells as contributors or modulators of NAFLD progression remains controversial as they have both protective/antifibrotic and deleterious effects during NAFLD.

\section{DISCUSSION}

The presence, regulation and function of NK cells during NAFLD remains controversial. There are several factors that may explain these potentially contradictory results including the only recently improved characterization of NK cell surface markers, and the identification of tissue-specific NK cells. Indeed, better characterization of NK cells using distinct intra- and extra-cellular markers and metabolic indicators, has revealed previously unknown distinct characteristics of peripheral, liver, and adipose-tissue NK cells; all are relevant to progression of NAFLD to NASH and liver fibrosis $(34,35,38,39)$.

Disease stage also greatly influences activation of NK cells, which negatively correlates with fibrosis level in the liver. Thus, apparent contradictory outcomes may reflect the differential function of NK cells at different stages of disease; active and beneficial at early stages of fibrosis but becoming detrimental upon losing anti-tumor capacity thereby contributing to tumor progression at later stages (37) (Figure 1).

To date, there have been attempts to generate NK cell-targeted therapeutic approaches to treat NAFLD/NASH focused on their inhibition/depletion. Studies utilizing genetic targeting of total NK cells [IL6Ra and Cfs1 (40), E4bp4 (48), and NCR1 (50)] have shown promising reduction of obesity, liver steatosis, and improved insulin signaling in mice fed with $\operatorname{HFD}(50,69)$. Also, antibody-mediated depletion of NK cells (NK1.1 and GM1) in HFD-fed mice correlated with lower infiltration of macrophages in adipose tissue and improved systemic insulin signaling but had no effects on reducing weight gain $(48,50)$. Nonetheless, the heterogeneity of NK cells, as well as the great influence of 
the microenvironment on controlling their functions, underlines the difficulty of developing a unique global strategy of NK cell depletion to successfully treat NAFLD/NASH.

Increasing evidence support the influence of metabolism in controlling NK cells and therefore the therapeutic potential of targeting metabolic regulators during NAFLD/NASH. These may include the use of mTOR inhibitors that have shown to efficiently reduce the cytotoxicity of NK cells $(59,60)$. However, this may have a detrimental impact at later stages of NASH progression, contributing to tumor development. In addition, the complex regulation of mTOR expression during NAFLD/NASH, changing at different stages of the disease; increased in children (38) but reduced in adults (39) difficult the targeting of this pathway as an effective approach to treat disease progression.

Targeting of other factors that regulate NK cell activation by influencing metabolism have also been proposed. i.e., TGF $\beta$ represses the expression of nutrient receptors, glycolytic capacity and OXPHOS overall reducing NK cell cytotoxicity, supporting that inhibiting TGF $\beta$ could restore NK cell function during NAFLD/NASH $(63,77)$.

Still, we lack in depth understanding of the role of metabolism in regulating liver tissue-resident NK cells that may be particularly susceptible to the extreme changes in metabolic conditions typical in the liver. This notion is supported by recent studies demonstrating the role of microenvironment in determining NK cell activity, particularly metabolism (57, 64), which may differentially influence the activation of NK cells in different organs. Future research in this direction will improve our knowledge on the tissue-specific metabolic pathways regulating NK cell activity, paving the way for the development of therapeutic strategies targeting NK cell metabolism to treat NAFLD/NASH.

In summary, the potential of therapeutic approaches targeting NK cell metabolism in NAFLD will greatly benefit from better characterization of NK cells; resident vs. recirculating

\section{REFERENCES}

1. Cotter TG, Rinella M. Nonalcoholic fatty liver disease 2020: the state of the disease. Gastroenterology. (2020) 158:1851-64. doi: 10.1053 /j.gastro.2020.01.052

2. Taylor RS, Taylor RJ, Bayliss S, Hagstrom H, Nasr P, Schattenberg $\mathrm{JM}$, et al. Association between fibrosis stage and outcomes of patients with nonalcoholic fatty liver disease: a systematic review and metaanalysis. Gastroenterology. (2020) 158:1611-25 e12. doi: 10.1053/j.gastro.2020. 01.043

3. Baffy G. Hepatocellular carcinoma in non-alcoholic fatty liver disease: epidemiology, pathogenesis, and prevention. J Clin Transl Hepatol. (2013) 1:131-7. doi: 10.14218/FCTH.2013.00005

4. Byun JS, Yi HS. Hepatic immune microenvironment in alcoholic and nonalcoholic liver disease. Biomed Res Int. (2017) 2017:6862439. doi: $10.1155 / 2017 / 6862439$

5. Parthasarathy G, Revelo X, Malhi H. Pathogenesis of nonalcoholic steatohepatitis: an overview. Hepatol Commun. (2020) 4:478-92. doi: 10.1002/hep4.1479

6. Gehrke N, Schattenberg JM. Metabolic inflammation-a role for hepatic inflammatory pathways as drivers of comorbidities in nonalcoholic fatty liver disease? Gastroenterology. (2020) 158:1929-47 e6. doi: 10.1053/j.gastro.2020.02.020 vs. blood. This would enable improved targeting strategies that account for the distinct tissue microenvironment and unique metabolic characteristics.

\section{AUTHOR CONTRIBUTIONS}

All authors listed have made a substantial, direct and intellectual contribution to the work, and approved it for publication.

\section{FUNDING}

This work was supported by grants from the Ministerio de Ciencia y Innovación, Gobierno España: SAF2017-87301-R and RTI2018-096759-A-100 integrado en el Plan Estatal de Investigación Científica y Técnica y Innovación, cofinanciado con Fondos FEDER (to ML-M-C and TD, respectively); Asociación Española contra el Cáncer (TD), 2018 BBVA Foundation Grants for Scientific Research Teams (to ML-MC). Ciberehd_ISCIII_MINECO was funded by the Instituto de Salud Carlos III. NB was funded by the BBSRC Institute Strategic Programme Gut Microbes and Health BBS/E/F/00044509, the BBSRC Institute Strategic Programme Gut Microbes and Health BB/R012490/1 and its constituent project BBS/E/F/000PR10355, and the BBSRC Core Capability Grant BB/CCG1860/1 as well as the BBSRC Institute Strategic Programme Food Innovation and Health BB/R012512/1 and its constituent project BBS/E/F/000PR10347.

\section{ACKNOWLEDGMENTS}

We thank MINECO for the Severo Ochoa Excellence Accreditation to CIC bioGUNE (SEV-2016-0644). We gratefully acknowledge the support of the Biotechnology and Biological Sciences Research Council (BBSRC). We would like to thank Judith Pell for editing the manuscript.
7. Wynn TA, Vannella KM. Macrophages in tissue repair, regeneration, and fibrosis. Immunity. (2016) 44:450-62. doi: 10.1016/j.immuni.2016.02.015

8. Eming SA, Wynn TA, Martin P. Inflammation and metabolism in tissue repair and regeneration. Science. (2017) 356:1026-30. doi: 10.1126/science.aam7928

9. Diedrich T, Kummer S, Galante A, Drolz A, Schlicker V, Lohse $A W$, et al. Schulze Zur Wiesch, Characterization of the immune cell landscape of patients with NAFLD. PLoS ONE. (2020) 15:e0230307. doi: 10.1371/journal.pone.0230307

10. Xiong X, Kuang H, Ansari S, Liu T, Gong J, Wang S, et al. Landscape of intercellular crosstalk in healthy and NASH liver revealed by single-cell secretome gene analysis. Mol Cell. (2019) 75:644-60 e5. doi: 10.1016/j.molcel.2019.07.028

11. Haas JT, Vonghia L, Mogilenko DA, Verrijken A, Molendi-Coste O, Fleury $\mathrm{S}$, et al. Transcriptional network analysis implicates altered hepatic immune function in NASH development and resolution. Nat Metab. (2019) 1:604-14. doi: 10.1038/s42255-019-0076-1

12. Li H, Zhou Y, Wang H, Zhang M, Qiu P, Zhang M, et al. Crosstalk between liver macrophages and surrounding cells in nonalcoholic steatohepatitis. Front Immunol. (2020) 11:1169. doi: 10.3389/fimmu.2020.01169

13. Kazankov K, Jorgensen SMD, Thomsen KL, Moller HJ, Vilstrup H, George $\mathrm{J}$, et al. The role of macrophages in nonalcoholic fatty liver disease and nonalcoholic steatohepatitis. Nat Rev Gastroenterol Hepatol. (2019) 16:14559. doi: 10.1038/s41575-018-0082-x 
14. van der Windt DJ, Sud V, Zhang H, Varley PR, Goswami J, Yazdani HO, et al. Neutrophil extracellular traps promote inflammation and development of hepatocellular carcinoma in nonalcoholic steatohepatitis. Hepatology. (2018) 68:1347-60. doi: 10.1002/hep.29914

15. Feng $\mathrm{D}$. The alteration of immune cells in the pathogenesis of non-alcoholic fatty liver disease and non-alcoholic steatohepatitis. Liver Res. (2020) 4:23-7. doi: 10.1016/j.livres.2020.02.003

16. Van Herck MA, Weyler J, Kwanten WJ, Dirinck EL, De Winter BY, Francque $\mathrm{SM}$, et al. The differential roles of $\mathrm{T}$ cells in non-alcoholic fatty liver disease and obesity. Front Immunol. (2019) 10:82. doi: 10.3389/fimmu.2019. 00082

17. Sutti S, Albano E. Adaptive immunity: an emerging player in the progression of NAFLD. Nat Rev Gastroenterol Hepatol. (2020) 17:81-92. doi: 10.1038/s41575-019-0210-2

18. Herberman RB, Nunn ME, Holden HT, Lavrin DH. Natural cytotoxic reactivity of mouse lymphoid cells against syngeneic and allogeneic tumors. II. Characterization of effector cells. Int J Cancer. (1975) 16:230-9. doi: 10.1002/ijc. 2910160205

19. Herberman RB, Nunn ME, Lavrin DH. Natural cytotoxic reactivity of mouse lymphoid cells against syngeneic acid allogeneic tumors. I. Distribution of reactivity and specificity. Int J Cancer. (1975) 16:216-29. doi: 10.1002/ijc.2910160204

20. Kiessling R, Klein E, Wigzell H. "Natural" killer cells in the mouse. I. Cytotoxic cells with specificity for mouse Moloney leukemia cells. Specificity and distribution according to genotype. Eur J Immunol. (1975) 5:112-7. doi: 10.1002/eji.1830050208

21. Kiessling R, Klein E, Pross H, Wigzell H. "Natural" killer cells in the mouse. II. Cytotoxic cells with specificity for mouse Moloney leukemia cells. Characteristics of the killer cell. Eur J Immunol. (1975) 5:117-21. doi: 10.1002/eji.1830050209

22. Mace EM, Dongre P, Hsu HT, Sinha P, James AM, Mann SS, et al. Cell biological steps and checkpoints in accessing NK cell cytotoxicity. Immunol Cell Biol. (2014) 92:245-55. doi: 10.1038/icb.2013.96

23. Orange JS. Formation and function of the lytic NK-cell immunological synapse. Nat Rev Immunol. (2008) 8:713-25. doi: 10.1038/nri2381

24. Nagler A, Lanier LL, Cwirla S, Phillips JH. Comparative studies of human FcRIII-positive and negative natural killer cells. J Immunol. (1989) 143:318391.

25. Nakatani K, Kaneda K, Seki S, Nakajima Y. Pit cells as liver-associated natural killer cells: morphology and function. Med Electron Microsc. (2004) 37:29-36. doi: 10.1007/s00795-003-0229-9

26. Mikulak J, Bruni E, Oriolo F, Di Vito C, Mavilio D. Hepatic natural killer cells: organ-specific sentinels of liver immune homeostasis and physiopathology. Front Immunol. (2019) 10:946. doi: 10.3389/fimmu.2019.00946

27. Vivier E, Tomasello E, Baratin M, Walzer T, Ugolini S. Functions of natural killer cells. Nat Immunol. (2008) 9:503-10. doi: 10.1038/ni1582

28. O'Leary JG, Goodarzi M, Drayton DL, von Andrian UH. T cell- and B cell-independent adaptive immunity mediated by natural killer cells. Nat Immunol. (2006) 7:507-16. doi: 10.1038/ni1332

29. Orr MT, Lanier LL. Natural killer cell education and tolerance. Cell. (2010) 142:847-56. doi: 10.1016/j.cell.2010.08.031

30. Thomas LM. Current perspectives on natural killer cell education and tolerance: emerging roles for inhibitory receptors. Immunotargets Ther. (2015) 4:45-53. doi: 10.2147/ITT.S61498

31. Oliviero B, Varchetta S, Paudice E, Michelone G, Zaramella M, Mavilio D, et al. Natural killer cell functional dichotomy in chronic hepatitis B and chronic hepatitis C virus infections. Gastroenterology. (2009) 137:1151-60, 1160 e1-7. doi: 10.1053/j.gastro.2009.05.047

32. Fasbender F, Obholzer M, Metzler S, Stober R, Hengstler JG, Watzl C. Enhanced activation of human NK cells by drug-exposed hepatocytes. Arch Toxicol. (2020) 94:439-448. doi: 10.1007/s00204-020-02668-8

33. Tan S, Xu Y, Wang Z, Wang T, Du X, Song X, et al. Tim-3 hampers tumor surveillance of liver-resident and conventional NK cells by disrupting PI3K signaling. Cancer Res. (2020) 80:1130-42. doi: 10.1158/0008-5472.CAN-19-2332

34. Stiglund N, Strand K, Cornillet M, Stal P, Thorell A, Zimmer CL, et al. Retained NK cell phenotype and functionality in non-alcoholic fatty liver disease. Front Immunol. (2019) 10:1255. doi: 10.3389/fimmu.2019.01255
35. Viel S, Besson L, Charrier E, Marcais A, Disse E, Bienvenu J, et al. Alteration of Natural Killer cell phenotype and function in obese individuals. Clin Immunol. (2017) 177:12-7. doi: 10.1016/j.clim.2016.01.007

36. O'Shea D, Cawood TJ, O'Farrelly C, Lynch L. Natural killer cells in obesity: impaired function and increased susceptibility to the effects of cigarette smoke. PLoS ONE. (2010) 5:e8660. doi: 10.1371/journal.pone.00 08660

37. Amer J, Salhab A, Noureddin M, Doron S, Abu-Tair L, Ghantous R, et al. Insulin signaling as a potential natural killer cell checkpoint in fatty liver disease. Hepatol Commun. (2018) 2:285-98. doi: 10.1002/hep4.1146

38. Tobin LM, Mavinkurve M, Carolan E, Kinlen D, O’Brien EC, Little $\mathrm{MA}$, et al. NK cells in childhood obesity are activated, metabolically stressed, and functionally deficient. JCI Insight. (2017) 2:e94939. doi: 10.1172/jci.insight.94939

39. Michelet X, Dyck L, Hogan A, Loftus RM, Duquette D, Wei K, et al. Metabolic reprogramming of natural killer cells in obesity limits antitumor responses. Nat Immunol. (2018) 19:1330-40. doi: 10.1038/s41590-018-0251-7

40. Theurich S, Tsaousidou E, Hanssen R, Lempradl AM, Mauer J, Timper K, et al. IL-6/Stat3-dependent induction of a distinct, obesity-associated NK cell subpopulation deteriorates energy and glucose homeostasis. Cell Metab. (2017) 26:171-84 e6. doi: 10.1016/j.cmet.2017.05.018

41. Cuff AO, Sillito F, Dertschnig S, Hall A, Luong TV, Chakraverty R, et al. The obese liver environment mediates conversion of $\mathrm{NK}$ cells to a less cytotoxic ILC1-like phenotype. Front Immunol. (2019) 10:2180. doi: 10.3389/fimmu.2019.02180

42. Kahraman A, Schlattjan M, Kocabayoglu P, Yildiz-Meziletoglu S, Schlensak M, Fingas CD, et al. Major histocompatibility complex class I-related chains A and B (MIC A/B): a novel role in nonalcoholic steatohepatitis. Hepatology. (2010) 51:92-102. doi: 10.1002/hep.23253

43. Fan Y, Zhang W, Wei H, Sun R, Tian Z, Chen Y. Hepatic NK cells attenuate fibrosis progression of non-alcoholic steatohepatitis in dependent of CXCL10mediated recruitment. Liver Int. (2020) 40:598-608. doi: 10.1111/liv.14307

44. Tosello-Trampont AC, Krueger P, Narayanan S, Landes SG, Leitinger N, Hahn YS. NKp46(+) natural killer cells attenuate metabolism-induced hepatic fibrosis by regulating macrophage activation in mice. Hepatology. (2016) 63:799-812. doi: 10.1002/hep.28389

45. Tian Z, Sun R, Wei H, Gao B. Impaired natural killer (NK) cell activity in leptin receptor deficient mice: leptin as a critical regulator in NK cell development and activation. Biochem Biophys Res Commun. (2002) 298:297302. doi: 10.1016/S0006-291X(02)02462-2

46. Cepero-Donates Y, Lacraz G, Ghobadi F, Rakotoarivelo V, Orkhis S, Mayhue $\mathrm{M}$, et al. Interleukin-15-mediated inflammation promotes non-alcoholic fatty liver disease. Cytokine. (2016) 82:102-11. doi: 10.1016/j.cyto.2016.01.020

47. Gomez-Santos L, Luka Z, Wagner C, Fernandez-Alvarez S, Lu SC, Mato JM, et al. Inhibition of natural killer cells protects the liver against acute injury in the absence of glycine N-methyltransferase. Hepatology. (2012) 56:747-59. doi: 10.1002/hep.25694

48. Lee BC, Kim MS, Pae M, Yamamoto Y, Eberle D, Shimada T, et al. Adipose natural killer cells regulate adipose tissue macrophages to promote insulin resistance in obesity. Cell Metab. (2016) 23:685-98. doi: 10.1016/j.cmet.2016.03.002

49. Boulenouar S, Michelet X, Duquette D, Alvarez D, Hogan AE, Dold $\mathrm{C}$, et al. Adipose type one innate lymphoid cells regulate macrophage homeostasis through targeted cytotoxicity. Immunity. (2017) 46:273-86. doi: 10.1016/j.immuni.2017.01.008

50. Wensveen FM, Jelencic V, Valentic S, Sestan M, Wensveen TT, Theurich S, et al. NK cells link obesity-induced adipose stress to inflammation and insulin resistance. Nat Immunol. (2015) 16:376-85. doi: 10.1038/ni.3120

51. Fujita K, Nozaki Y, Wada K, Yoneda M, Fujimoto Y, Fujitake M, et al. Dysfunctional very-low-density lipoprotein synthesis and release is a key factor in nonalcoholic steatohepatitis pathogenesis. Hepatology. (2009) 50:772-80. doi: 10.1002/hep.23094

52. Gao B. Natural killer group 2 member D, its ligands, and liver disease: good or bad? Hepatology. (2010) 51:8-11. doi: 10.1002/hep.23320

53. Cerboni C, Zingoni A, Cippitelli M, Piccoli M, Frati L, Santoni A. Antigenactivated human $\mathrm{T}$ lymphocytes express cell-surface NKG2D ligands via an ATM/ATR-dependent mechanism and become susceptible to autologous NKcell lysis. Blood. (2007) 110:606-15. doi: 10.1182/blood-2006-10-052720 
54. Kloss M, Decker P, Baltz KM, Baessler T, Jung G, Rammensee HG, Steinle A, Krusch M, Salih HR. Interaction of monocytes with NK cells upon Toll-like receptor-induced expression of the NKG2D ligand MICA. J Immunol. (2008) 181:6711-9. doi: 10.4049/jimmunol.181.10.6711

55. O'Neill LA, Kishton RJ, Rathmell J. A guide to immunometabolism for immunologists. Nat Rev Immunol. (2016) 16:553-65. doi: 10.1038/nri.2016.70

56. Felices M, Lenvik AJ, McElmurry R, Chu S, Hinderlie P, Bendzick L, et al. Continuous treatment with IL-15 exhausts human NK cells via a metabolic defect. JCI Insight. (2018) 3:e96219. doi: 10.1172/jci.insight.96219

57. Keating SE, Zaiatz-Bittencourt V, Loftus RM, Keane C, Brennan K, Finlay DK, et al. Metabolic reprogramming supports IFN-gamma production by CD56bright NK cells. J Immunol. (2016) 196:2552-60. doi: 10.4049/jimmunol.1501783

58. Keppel MP, Saucier N, Mah AY, Vogel TP, Cooper MA. Activation-specific metabolic requirements for NK Cell IFN-gamma production. I Immunol. (2015) 194:1954-62. doi: 10.4049/jimmunol.1402099

59. Donnelly RP, Loftus RM, Keating SE, Liou KT, Biron CA, Gardiner $\mathrm{CM}$, et al. mTORC1-dependent metabolic reprogramming is a prerequisite for NK cell effector function. J Immunol. (2014) 193:4477-84. doi: 10.4049/jimmunol.1401558

60. Marcais A, Cherfils-Vicini J, Viant C, Degouve S, Viel S, Fenis A, et al. The metabolic checkpoint kinase mTOR is essential for IL-15 signaling during the development and activation of NK cells. Nat Immunol. (2014) 15:749-57. doi: 10.1038/ni.2936

61. Assmann N, O’Brien KL, Donnelly RP, Dyck L, Zaiatz-Bittencourt V, Loftus $\mathrm{RM}$, et al. Srebp-controlled glucose metabolism is essential for NK cell functional responses. Nat Immunol. (2017) 18:1197-206. doi: 10.1038/ni.3838

62. Loftus RM, Assmann N, Kedia-Mehta N, O’Brien KL, Garcia A, Gillespie $\mathrm{C}$, et al. Amino acid-dependent cMyc expression is essential for NK cell metabolic and functional responses in mice. Nat Commun. (2018) 9:2341. doi: 10.1038/s41467-018-04719-2

63. Zaiatz-Bittencourt V, Finlay DK, Gardiner CM. Canonical TGF-beta signaling pathway represses human NK cell metabolism. J Immunol. (2018) 200:393441. doi: 10.4049/jimmunol.1701461

64. Salzberger W, Martrus G, Bachmann K, Goebels H, Hess L, Koch M, et al. Tissue-resident NK cells differ in their expression profile of the nutrient transporters Glut1, CD98 and CD71. PLoS ONE. (2018) 13:e0201170. doi: 10.1371/journal.pone.0201170

65. Hirsova P, Weng P, Salim W, Bronk SF, Griffith TS, Ibrahim SH, et al. TRAIL deletion prevents liver, but not adipose tissue, inflammation during murine diet-induced obesity. Hepatol Commun. (2017) 1:648-62. doi: 10.1002/hep4.1069

66. Idrissova L, Malhi H, Werneburg NW, LeBrasseur NK, Bronk SF, Fingas C, et al. TRAIL receptor deletion in mice suppresses the inflammation of nutrient excess. J Hepatol. (2015) 62:1156-63. doi: 10.1016/j.jhep.2014.11.033

67. Beraza N, Malato Y, Sander LE, Al-Masaoudi M, Freimuth J, Riethmacher D, et al. Hepatocyte-specific NEMO deletion promotes NK/NKT celland TRAIL-dependent liver damage. J Exp Med. (2009) 206:1727-37. doi: $10.1084 /$ jem.20082152
68. Bhattacharjee J, Kumar JM, Arindkar S, Das B, Pramod U, Juyal RC, et al. Role of immunodeficient animal models in the development of fructose induced NAFLD. J Nutr Biochem. (2014) 25:219-26. doi: 10.1016/j.jnutbio.2013.10.010

69. O’Rourke RW, Meyer KA, Neeley CK, Gaston GD, Sekhri P, Szumowski $\mathrm{M}$, et al. Systemic NK cell ablation attenuates intra-abdominal adipose tissue macrophage infiltration in murine obesity. Obesity. (2014) 22:2109-14. doi: 10.1002/oby.20823

70. Gur C, Doron S, Kfir-Erenfeld S, Horwitz E, Abu-Tair L, Safadi R, et al. NKp46-mediated killing of human and mouse hepatic stellate cells attenuates liver fibrosis. Gut. (2012) 61:885-93. doi: 10.1136/gutjnl-2011-301400

71. Li T, Yang Y, Song H, Li H, Cui A, Liu Y, et al. Activated NK cells kill hepatic stellate cells via p38/PI3K signaling in a TRAIL-involved degranulation manner. J Leukoc Biol. (2019) 105:695-704. doi: 10.1002/JLB.2A0118-031RR

72. Melhem A, Muhanna N, Bishara A, Alvarez CE, Ilan Y, Bishara T, et al. Anti-fibrotic activity of NK cells in experimental liver injury through killing of activated HSC. J Hepatol. (2006) 45:60-71. doi: 10.1016/j.jhep.2005. 12.025

73. Muhanna N, Abu Tair L, Doron S, Amer J, Azzeh M, Mahamid M, et al. Amelioration of hepatic fibrosis by NK cell activation. Gut. (2011) 60:90-8. doi: 10.1136/gut.2010.211136

74. Radaeva S, Sun R, Jaruga B, Nguyen VT, Tian Z, Gao B. Natural killer cells ameliorate liver fibrosis by killing activated stellate cells in NKG2D-dependent and tumor necrosis factor-related apoptosisinducing ligand-dependent manners. Gastroenterology. (2006) 130:435-52. doi: 10.1053/j.gastro.2005.10.055

75. Wu J, Wu D, Zhang L, Lin C, Liao J, Xie R, et al. NK cells induce hepatic ER stress to promote insulin resistance in obesity through osteopontin production. J Leukoc Biol. (2020) 107:589-96. doi: 10.1002/JLB.3MA1119-173R

76. O'Sullivan TE, Rapp M, Fan X, Weizman OE, Bhardwaj P, Adams $\mathrm{NM}$, et al. Adipose-resident group 1 innate lymphoid cells promote obesity-associated insulin resistance. Immunity. (2016) 45:428-41. doi: 10.1016/j.immuni.2016.06.016

77. Viel S, Marcais A, Guimaraes FS, Loftus R, Rabilloud J, Grau M, et al. TGF-beta inhibits the activation and functions of NK cells by repressing the mTOR pathway. Sci Signal. (2016) 9:ra19. doi: 10.1126/scisignal. aad1884

Conflict of Interest: The authors declare that the research was conducted in the absence of any commercial or financial relationships that could be construed as a potential conflict of interest.

Copyright (c) 2021 Martinez-Chantar, Delgado and Beraza. This is an open-access article distributed under the terms of the Creative Commons Attribution License (CC $B Y)$. The use, distribution or reproduction in other forums is permitted, provided the original author(s) and the copyright owner(s) are credited and that the original publication in this journal is cited, in accordance with accepted academic practice. No use, distribution or reproduction is permitted which does not comply with these terms. 